\title{
Research on Extensive Interpretation and Analogical Interpretation of Criminal Law
}

\author{
Wenchao Li \\ Hainan Vocational College of Political Science and Law, Haikou Hainan, 571100, China
}

Keywords: Interpretation of criminal law, Boundary, Approach.

\begin{abstract}
According to the principle of a legally prescribed punishment for a specified crime, criminal rules shall be rules and norms that are clearly worded and enable national to predict probabilities. In present justice practice, any vague in meaning of criminal law certainly will demand judge to weigh multiple complex legal relations within his discretion before deciding applicable laws to specific case, increasing judicial cost. Besides, the relative stability of criminal rules gradually appear lagging with social development. Thus, judge is supposed to appropriately interpret the existing criminal law system for specific cases. Furthermore, the normativity of criminal law also determines that once any doubt on any clauses of criminal law arises in any specific case, judge shall reasonably clear up such doubt with an appropriate interpretation method. This shows the necessity and importance of interpretation of criminal law. On this basis, this thesis is written to discuss the border and approach of criminal law interpretation.
\end{abstract}

\section{Introduction}

Criminal law interpretation means, superficially, making clear the contents of criminal law, and deeply, protecting the stability of criminal law and safeguarding the uniformity of legal system. For a country, the existence of criminal law interpretation is an essential assurance for the country to establish a complete criminal law system. Beccaria said "the life and freedom of the unfortunate are deprived of by absurd seasoning or emotional impulse of some judge.” This shows the significance of interpretation of criminal law to judge and the people. In order to overcome the arbitrariness of the interpretations to criminal law, the boundary between extensive interpretation and analogical interpretation should be recognized.

\section{Overview of Criminal Law Interpretation}

Criminal law interpretation means interpreting articles or clauses of laws. Since the contents represented by clauses in the criminal law are abstract and stable, criminal law interpretation is needed to facilitate correct comprehension of the legislative intention and accurate application thereof, and to avoid misunderstanding. There are three types of criminal law interpretation, i.e. legislative interpretation, judicial interpretation and academic interpretation ${ }^{[1]}$. Legislative interpretation refers to the legislature interpreting the meaning of criminal law. Legislative interpretation is as effectual as legislation, so it can be used to make up the deficiency of criminal law, to achieve high adaptability and safeguard the stability of criminal law. Judicial interpretation refers to judiciary authorities interpreting the intended meaning of criminal law. Judicial interpretation is mainly adopted to determine the application of criminal law. Both the foregoing two types are authoritative interpretation, and are legally binding for this reason. In contrast, academic interpretation is unauthoritative, and is not legally binding. Notwithstanding, the reference significance of academic interpretation cannot be ignored. Besides, the methods of criminal law interpretation include literal rule and logical interpretation, and the latter covers extensive interpretation, restrictive interpretation, natural interpretation, and historical interpretation.

In the theory criminal law, criminal law interpretation is divided into subjective interpretation and objective interpretation. According to the viewpoint of subjective interpretation, it is advocated that 
"law is the code of conduct designed by the lawmaker to regulate people, conveying the subjective wishes of the lawmaker, such as hoping people to or not to or allowing people to or not to do something." This viewpoint stresses the definiteness of criminal law, which is designed to regulate people's action fashion in social activities, and highlights that even if the execution of power within the extend of competence by law infringes the legitimate rights of citizens, extra-legal sanctions shall not be imposed. In the viewpoint of objective interpretation, it is insisted that "legal interpretation shall not departure from actual social activities" ${ }^{[2]}$, highlighting that once the law is divorced from or fail to adapt to social needs, the law will be enervated. In this viewpoint, however, the comprehending is apparently deviated. That is, the primary meaning of interpretation is confused. Thus, the boundary between legislation and judicature is not clearly defined. In fact, criminal law interpretation shall be made based on the principle a legally prescribed punishment for a specified crime, shall not go beyond the criminal legislation power, and shall insist on strict interpretation. It needs to be noted that criminal law interpretation shall be to explain the legislative spirit within the scope allowed by legislative implication to make up legislation deficiency.

\section{Boundary of Criminal Law Interpretation-Based on Extensive Interpretation and Analogical Interpretation}

Recognizing the boundary between extensive interpretation and analogical interpretation is the essential to overcome the arbitrariness of the interpretations to criminal law, as follows.

Extensive interpretation refers to presenting a more extensive meaning of clauses of criminal law than their ordinary meaning within the limitation of meaning intended by the wording of clauses of criminal law. In brief, the "extensive" in extensive interpretation is relative to the ordinary meaning intended by the wording of clauses of criminal law, namely an extensive form of the ordinary meaning intended by the wording of clauses of criminal law ${ }^{[3]}$. The literal meaning of clauses of criminal law includes the likely implications, but will not surpass the boundary of "meaning domain”. Otherwise, it is not extensive interpretation. The meaning intended by the wording of clauses of criminal law is divided into core meaning and fringe meaning. By this, extensive interpretation means extending the meaning of the wording of clauses of criminal law from the ordinary (core) meaning to the fringe meaning. Conclusions drawn by extensive interpretation will not surpass the literal meaning of the wording of clauses of criminal law, which is the basic difference between extensive interpretation and analogical interpretation. For example, Clause 49 of criminal law provides: "the death penalty shall not be imposed on women who are pregnant at the time of trial." By "at the time of trial", it means the whole litigation procedure from detention to execution. At the final judgment phase of death sentence with immediate execution, once the woman/women to be executed is/are found to be pregnant, the execution shall be stopped immediately ${ }^{[4]}$. In this case, extensive interpretation is applied.

Analogical interpretation refers to imposing legal effect of clauses applicable to expressly stipulated items on ones which are neither expressly stipulated nor covered by the literal meaning of the wording of clauses of criminal law, but are similar to some expressly stipulated ones. The precondition for analogical interpretation is that there is any item not expressly stipulated in law occurring. In essential, extensive interpretation and analogical interpretation are largely different. Analogical interpretation is a method to be adopted for handling items which are neither specifically nor concretely stipulated by law.

Extensive interpretation also differs from analogical interpretation in construction, as below:

First, "whether included in the likely implications of the wording of clauses of criminal law". Conclusions drawn by extensive interpretation and that by analogical interpretation are and are not included in the likely implications of the wording of clauses of criminal law, respectively. The literal meaning of the wording of clauses of criminal law always covers items to be dealt with.

Second, prediction possibility of citizens. Conclusions drawn by extensive interpretation will not go beyond the prediction possibility of citizens, and that by analogical interpretation will. For example, Clause 252 of the Criminal Law provides that "whoever damages or discards other's mail 
shall be punished". Yet if "some one illegally delete other's e-mail” in a real case, whether this person shall be punished according to Clause 252? The basis for applying this clause is that "mail” includes paper mail and e-mail, which is extensive interpretation conforming to prediction possibility of citizens. Conclusions drawn by analogical interpretation will go beyond the prediction possibility of citizens. For example, Clause 236 (1) of the whoever rapes a woman by violence or coercion shall be punished. If this clause is applied in the case that "a woman rapes a man by violence or coercion", it falls into analogical interpretation ${ }^{[5]}$.

Third, whether presumption conforms to formal logic. Extensive interpretation differs from analogical interpretation in the mode of thinking. The former conforms to formal logic presumption (emphasize the prescription of the major premise, and deduce from inside to outside between the major premise and the minor premise), while the latter conforms to material investigation (emphasize comparison of items, and conclude outside-in between the items to be dealt with and the items to be interpreted).

Fourth, whether based on the principle of a legally prescribed punishment for a specified crime. Extensive interpretation is based on the principle of a legally prescribed punishment for a specified crime, while analogical interpretation on social demand for punishment. For example, Clause 259 of the Criminal Law, which provides violation of the PLA man's marriage, has different conceptions by extensive interpretation and by analogical interpretation. By the former, it is insisted that "only the one who knowingly commits adultery with the spouse of a soldier for a long time shall be punished, while by the latter, it is insisted that "whoever knowingly commits adultery with the spouse of a soldier occasionally and causes grave consequences shall be punished”.

\section{Approach of Criminal Law Interpretation-Based on Extensive Interpretation and Analogical Interpretation}

Besides that the boundary between extensive interpretation and analogical interpretation shall be recognized, the approach of extensive interpretation also shall be recognized. The steps are as below.

Step 1, determine object. Determine the nature of items to be dealt with, lest the items fall out of the object of extensive interpretation. Since the clauses to be interpreted are non-reifiable criteria for judging, extensive interpretation means figuring out the concrete meanings based on the abstract definitions. This indicates that the object of extensive interpretation are not parallel to but contained by the clauses to be interpreted and items to be dealt with. For example, the object to be interpreted is "lethal weapon", then the items to be dealt with can contain "gun, knife, sulfuric acid, club or stone, etc.", indicating that the object of interpretation is in a containment relationship with the items to be dealt with. If "gun" becomes the object of interpretation, then the items to be dealt with cannot contain "knife, sulfuric acid, club or stone, etc.". In that case, the object of interpretation is parallel to the items to be dealt with. Besides, for the object of extensive interpretation, the clauses to be interpreted are not closed, but the items to be dealt with are. For example, "prostitution" may become an object of interpretation, of which the subject and action fashion are not undiversified; while "male" can be taken as an item to be dealt with only, because its concept is clear. Only items meeting the characteristics as above can be taken as object of extensive interpretation.

Step 2, get a conclusion. Conclusion shall be got by forward extension (ordinary meaning of clauses of criminal law) and reverse restriction (necessity of punishment) based on prediction possibility of citizens. The primary task is to determine the ordinary meaning of clauses to be interpreted (based on the general usage of clauses of criminal law). For example, in daily life, "person" refers to another person, self and brain-dead person, excluding embryo. If a crime is determined to be "intentional homicide", then the person as defined above may become the victim. Yet if a crime is determined by extensive interpretation to be "intentional homicide", then the victim scope is broadened to include "embryo going to become nine months and keeping fetal movement". Besides, the fringe meaning of clauses to be interpreted shall be figured out. From the perspective of extensive interpretation, the extreme limit of meaning of clauses of criminal law may be closely 
related to predication possibility of citizens. The "degree", however, shall be properly grasped. The boundary is whether the meaning of clauses of criminal law can be infinitely forward extended. If so, it is analogical interpretation, otherwise it is extensive interpretation.

Step 3, check the conclusion. Check the conclusion by means of legal negotiation, and determine the nature. Since parties interested are different in the case of conclusions drawn by extensive interpretation and by analogical interpretation, the boundary between extensive interpretation and analogical interpretation tend to be not clear enough. With different standpoints, the parties interested have different emphases. In a word, if a conclusion favorable to the defendant is drawn, the defendant and the defender will insist that the conclusion is drawn by extensive interpretation and shall be adopted; while the victim and the public prosecutor will insist that the conclusion is drawn by analogical interpretation and shall be prohibited. In that case where both sides ends in a deadlock, the conclusion shall be checked by means of legal negotiation. If the parties interested continue to debate fully, coercively and twistedly, then the judge also cannot determine whether extensive interpretation or analogical interpretation was adopted. If based on the principle that criminal defendant be favoured when evident doubtful, it still cannot be verified that the conclusion weighted against the defendant was drawn by extensive interpretation, then the conclusion shall not be adopted.

Step 4, eliminate divergence. It is necessary to eliminate divergence relating to substantive matters in a procedural manner. If no agreement is not reached despite full legal negotiation, the conclusion shall be deemed to be drawn by analogical interpretation. The application of procedural dispute resolution aims to settle divergence relating to substantive matters that always exist, to achieve peace through law. Once any party interested or unconcerned third person raises an objection to the decision of judge that a certain interpretation falls into extensive interpretation, only "procedural means" can be resorted to, so as to change the ideas of the party interested or unconcerned third person. Specifically, the party interested or unconcerned third person submits his dissenting views to the higher authorities for examination and approval according to procedural requirements. If the conclusion by extensive interpretation concerns a wide scope, it shall be guaranteed that the dissenting views of the party interested or unconcerned third person are examined and approved by the Supreme People's Court and even the Standing Committee of the National People's Congress.

\section{Conclusion}

To sum up, the significance of criminal law interpretation is to make law benefit people in the most just, open and fair manner. The discussions above show that extensive interpretation largely differs from analogical interpretation in respect of presumption conforming to formal logic or whether the principle of a legally prescribed punishment for a specified crime is based on. In recent years, some Chinese criminal law experts have made analyses on the boundary between extensive interpretation and analogical interpretation. Some concluded that the former was more convenient to apply, while others realized that analogical interpretation was not always applicable if the principle of a legally prescribed punishment for a specified crime was based on.

\section{References}

[1] Feng Jun. On Extensive Interpretation and Analogical Interpretation of Criminal Law : A Study of the Distinction between Analogical Interpretation and Difference of Constitution, Jurist, 2012, 13001:63-75+177.

[2] Shi Juhang. Pressure In Respect Of Rule By Law Of Criminal Law Interpretation And Mitigation Measures Therefor, Journals of People's Public Security University of China (Social Science Edition), 2015, 31(17604):79-88.

[3] Wang Huawei. Research On Retrospective Effect Of Criminal Law Interpretation, Journal of Chengdu University of Technology (Social Sciences),2014,v.22;No.8202:32-37. 
[4] Zhao Chunyu. Approach and Method of Legally Prescribed Punishment for A Specified Crime-Concentrating on Categorical Thinking in Criminal Law, Modern Law Science, 2014, 36, 19303:116-132.

[5] Li Yulei, Jiang Yonghong. Brief Discussion on Determination of Crime Boundary, Legal and Economic (middle ten-day), 2013, 36210:37-38. 